\title{
Effect of Taurine Supplements on Fat Absorption in Cystic Fibrosis
}

\author{
PAULINE B. DARLING, GUY LEPAGE, CLAUDIE LEROY, PIERRE MASSON, AND \\ CLAUDE C. ROY \\ Departments of Pediatrics and Nutrition and Hopital Ste-Justine, University of Montreal Montreal, Quebec, \\ Canada
}

\begin{abstract}
Patients with cystic fibrosis have an increased proportion of glycine conjugated bile acids with diminished tauroconjugates which could contribute to fat malabsorption. Twenty-two CF children with documented steatorrhea were supplemented with taurine capsules (30 $\mathrm{mg} / \mathrm{kg} /$ day) and placebo during separate 6-month treatment periods. Alteration of the glycine/taurine conjugation pattern was verified in two patients who showed a predominance of tauroconjugates as a result of taurine supplementation. On taurine, steatorrhea was reduced $(p<0.05)$ by $17.6 \pm 9.7 \%$ in 19 patients who completed the study as was the excretion of long-chain saturated fatty acids. There was no change in linoleic acid (C 18:2) excretion. In the 10 patients with a more severe degree of steatorrhea the decrease in fat loss approached $20 \%$ and a close relationship was found $(r=0.84, p<0.01)$ between the extent of the fatty acid loss on placebo and the decrease of this loss on taurine. A linear relationship was found between the percentage decrease of individual fatty acids and their log solubility in water. No change was found in the daily excretion of bile acids, neutral sterols, and nitrogen. Fasting plasma fatty acids, cholesterol, and triglycerides were also unchanged. Monitoring of growth over the two 6month periods revealed a marginal $(p<0.1)$ increase of weight velocity expressed as a percentage expected for age $(83.4 \pm 11.3 \rightarrow 117.1 \pm 16.5)$. The increase in height velocity in response to taurine showed a more modest trend $(95.3 \pm 7.8 \rightarrow 110.7 \pm 10.6)$. These data provide some support for the use of taurine supplements as an adjuvant form of therapy, particularly in patients with a more severe degree of steatorrhea. Additional clinical testing is warranted before recommending its general use. (Pediatr Res 19: 578-582, 1985)
\end{abstract}

Abbreviations

CF, cystic fibrosis

$\mathrm{G} / \mathrm{T}$, glycine/taurine

In recent years, taurine has been the subject of increasing interest in view of its role on the developing retina, the central nervous system, liver function, and growth $(1-3)$. There is dietary

Received October 25, 1984: accepted February 12, 1985

Correspondence Claude C. Roy, M.D. Pediatric Research Center, Hopital SteJustine, 3175 Ste-Catherine Road, Montreal, Quebec H3T 1 C5.

This study was supported by the Canadian Cystic Fibrosis Foundation and by the Medical Research Council of Canada. P.B.D. was the recipient of a studentship by the Canadian Cystic Fibrosis Foundation. dependence in so far as man cannot synthesize sufficient amounts to maintain normal levels. It fits the definition of a "conditionally essential" nutrient because needs cannot be met when dietary intake is inadequate or when losses are increased (1).

The only well-characterized metabolic reaction of taurine is its conjugation with bile acids in the liver. Conjugation of bile acids is catalyzed by a single enzyme, n-acetyl transferase, which has greater affinity for taurine than for glycine. The percentage of bile acids conjugated with taurine is closely correlated with the hepatic pool of taurine which in turn is dependent on the dietary intake (4). The $\mathrm{G} / \mathrm{T}$ ratio of conjugated bile acids increases in newborns on taurine-free formulas (5), in patients on TPN $(6,7)$, short bowel syndrome (8), and CF (9).

The increased $G / T$ ratio of bile acids found in $C F(9)$ has been confirmed by others $(10,11)$ and attributed to malabsorption of bile acids. Although fasting (11) and postcholecystokynin (10) total duodenal bile acids may be above the critical micellar concentration, it is likely that a significant proportion may not be physiologically available for the micellar solubilization of lipolytic products. Glycoconjugates have a much higher $\mathrm{pKa}$ than tauroconjugates $(3.8-4.3$ versus 1.8$)$ and, therefore, may not remain in micellar solution in the acidic duodenum of patients with pancreatic insufficiency (12). A further disadvantage of preponderant glycoconjugates with regard to fat absorption is that they are in part passively absorbed in the proximal portion of the absorptive apparatus $(13,14)$. Since tauroconjugates are mostly absorbed in the ileum (13) and are more resistant to bacterial degradation (15), they are more available to form mixed micelles with fat which may have escaped absorption proximally.

The purpose of this study was to test the hypothesis that the predominance of glycine conjugates with almost complete disappearance of tauroconjugates in certain cases (16) could play a significant role in the fat malabsorption of $\mathrm{CF}$. Herein we report the results of a randomized cross-over trial of taurine supplementation.

\section{PATIENTS AND METHODS}

Twenty-two CF children, 14 boys and eight girls, with a mean age of $75 / 12$ yr (2-16 yr) were admitted to the study on documentation of steatorrhea off pancreatic enzymes (>5 g/24 h). Two patients had hepatomegaly but no echographic evidence of cirrhosis. Bilirubin and aspartate aminotransferase levels were normal; however, seven patients had either a fasting or a 90-min postprandial level of cholylglycine (Radioimmunoassay diagnostic kit, Abbott Laboratories, Ltd., Montreal, Quebec) above 100 $\mu \mathrm{g} / \mathrm{dl}$. The average height as percentage of expected height for age (17) was 97.1 (88.4-105.4) while weight as percentage of expected weight for height (17) averaged $101.0(86.5-123.6)$. The 
Shwachman score (18) ranged from 64-98 with a mean of 84 . The study protocol was approved by the Ethics Committee of Hôpital Ste-Justine and informed consent was obtained from the parents.

Patients were randomly assigned to receive either taurine $(30$ $\mathrm{mg} / \mathrm{kg} /$ day) or placebo (lactose) during an initial 6-month period after which each patient received the alternate supplement during a second 6-month period. The study was carried out on an ambulatory basis and the children continued to consume their usual diet containing $40-45 \%$ fat. With regard to pancreatic enzyme therapy, the type (Pancrease) and number of capsules taken remained the same during the study except in three patients in whom a change from Cotazyme to Pancrease was made. In two of these patients, the switch to Pancrease occurred while they were on placebo. Vitamin supplementation and physiotherapy were maintained. Oral cloxacillin was continued for the entire duration of the study in 13 patients. Cloxacillin was used intermittently in the others.

Seventy-two hour stool collections were obtained between carmine red markers at the end of each 6-month period. Stools were frozen on evacuation and kept in the home freezer until the scheduled clinic appointments. On delivery to the laboratory feces were weighed, diluted with water $(1: 1, v / v)$, and homogenized. The stool homogenates were diluted with ethanol $90 \%$ $(1: 1, \mathrm{v} / \mathrm{v})$ in order to prevent further degradation of bile acids (19). The homogenates were then kept at $-20^{\circ} \mathrm{C}$ until subsequent analysis for fatty acids, bile acids, neutral sterols, and nitrogen.

Fecal fat. Fecal fat was quantitated by a recently described technique (20). This method consists of the analysis of total fatty acids by gas-liquid chromatography. Unlike currently used methods which require numerous preparative steps, this technique involves a one-step reaction which is carried out in the same tube, thereby leading to a more complete recovery of fatty acid constituents of all classes of lipids. Briefly, the stool homogenate, from which ethanol was removed under nitrogen, was added with an internal standard consisting of tridecanoic acid dissolved in methanol:benzene, $3: 2(\mathrm{v} / \mathrm{v})$. Direct transesterification was then carried out by adding $1 \mathrm{ml}$ of acetyl chloride:methanol, $5: 100(\mathrm{v} / \mathrm{v})$ to the stool and internal standard mixture. The closed tube was then heated at $100^{\circ} \mathrm{C}$ for $1 \mathrm{~h}$. Following the reaction, $1 \mathrm{ml}$ of an external standard solution, consisting of $500 \mu \mathrm{g}$ of methylated pentadecanoic acid dissolved in hexane, was added to the reaction mixture along with $1 \mathrm{ml}$ of distilled water. After centrifugation, an aliquot of the upper phase containing the methyl esters was injected into the gas chromatograph, a HewlettPackard 5880 equipped with a flame ionization detector. A 10$\mathrm{ft}$ glass column with an internal diameter of $2 \mathrm{~mm}$ and packed with 5\% SP-2340 on chromosorb W-AW (100-120 mesh) was used. Individual fatty acids were determined based on known quantities of the internal standard.

Fecal bile acids, neutral sterols, and nitrogen. Fecal bile acids and neutral sterols were measured from the aqueous ethanolic fecal homogenates of patients who excreted more than $10 \mathrm{~g}$ of fatty acids per day on placebo. Each determination was carried out in duplicate and the coefficient of variation did not exceed $10 \%$. After weighing, the internal standard, 23-nor-deoxycholic acid, was added to the homogenate. Following alkaline hydrolysis and acidification, free bile acids were extracted and thin layer chromatography was used to remove remnant lipids. Derivatization of bile acids was performed using a solution of acetyl chloride - methanol, followed by heating. Total and individual bile acids were quantitated with a Hewlett-Packard 5880 gas chromatograph using a 6-foot column packed with $2 \% \mathrm{QF} 1$ on chromasorb W (HP) 100:120 mesh. Samples for neutral sterol determination were added with the internal standard $5 \alpha$-cholestane. The mixture was refluxed with $\mathrm{NaOH}$-ethanol for one hour and then extracted with petroleum ether (21). The same column as for bile acids was used for gas liquid chromatography of neutral sterols. Fecal nitrogen was determined in duplicate by a modified Kjeldahl procedure (22).
Blood was collected after an overnight fast in Vacutainer tubes containing EDTA. Plasma was rapidly separated and stored at $-20^{\circ} \mathrm{C}$ until analysis of fatty acids using the same technique as the one summarized above for fecal homogenates. Cholesterol was measured with the modified Liebermann-Burchard reagent and was determined simultaneously with triglycerides using a Technicon autoanalyzer (23). Bile samples were obtained in two patients while on placebo and on taurine through a weighted polyethylene tube positioned in the second portion of the duodenum following the iv injection of cholecystokynin-pancreozymin $(1.5 \mathrm{U} / \mathrm{kg})$.

At the end of each treatment period, a questionnaire was addressed to the parents prior to clinic visits during which answers were verified. Particular attention was paid to appetite, frequency and consistency of stools, abdominal pain, and bloating. During trimonthly clinic visits anthropometric measurements were made. Height and weight velocities during the placebo and taurine treatment periods were compared to the standards of Tanner et al. (24) and expressed as a percentage of expected velocities for age during each 6-month period.

All results are expressed as $\bar{x} \pm \mathrm{SE}$. Response to taurine was evaluated using paired and unpaired Student's $t$ tests as described for the analysis of a cross-over clinical trial (25). Testing for linearity of regression between percentage decrease of individual fatty acids and their respective log solubility values was done using analysis of variance technique (26).

\section{RESULTS}

Of the 22 original patients, three dropped out of the study because of lack of compliance. Appetite and gastrointestinal manifestations did not change. However, constipation was noted in one patient on $1.4 \mathrm{~g}$ of taurine which was then decreased to $0.9 \mathrm{~g}$. During the two treatment periods, four patients had to be admitted to hospital for exacerbations of pulmonary disease requiring iv antibiotic therapy while receiving placebo and three during the treatment period with taurine. The Shwachman scores of the 19 patients completing the 1-yr study did not change. In response to taurine, the ratio of $\mathrm{G} / \mathrm{T}$ conjugated bile acids changed from 7.05 to 1.19 in the two patients in whom bile was obtained during both periods of the study.

As illustrated in Figure 1, most patients (14/19) showed a decrease of steatorrhea which overall was reduced by $17.6 \pm$ $9.7 \%$ while on taurine. This significant $(p<0.05)$ effect of taurine was particularly evident for long-chain saturated fatty acids. They were consistently reduced except for C14:0 (Table 1). Linolenic acid (C18:3) was decreased 2-fold but there was little change in linoleic acid (C18:2). Taurine was somewhat more beneficial in the 10 patients with a greater degree of steatorrhea $(>10 \mathrm{~g} /$ day $)$. In that group, the percentage decrease of fat loss approached $20 \%$ and a close relationship was observed $(r=0.84, p<0.01)$ between fatty acid loss on placebo and the improvement observed while on taurine. The percentage decrease of individual fatty acids accounting for $75 \%$ of total fat was plotted against their respective values for log solubility in water (27). A linear relationship was found between both variables since the percentage reduction of fatty acid loss increased as their individual aqueous solubility decreased (Fig. 2).

In contrast to fatty acids, neither the excretion of neutral sterols nor of acidic sterols (bile acids) was changed by the administration of taurine (Table 2). In the majority of patients $(7 / 10)$, neutral sterols consisted only of cholesterol as coprostanol and coprostanone were totally absent. Little change was noted in total bile acid excretion. The percentage of primary bile acids (cholic and chenodeoxycholic acid) during the placebo period was $54.7 \pm 7.7$ and $53.1 \pm 9.4 \%$ on taurine. The ratio of these two primary bile acids added with their respective degradation products which are formed by the intestinal flora was the same on placebo $(1.50 \pm 0.15)$ as on taurine $(1.67 \pm 0.15)$.

Nitrogen excretion during the placebo period was $1.78 \pm 0.18$ 


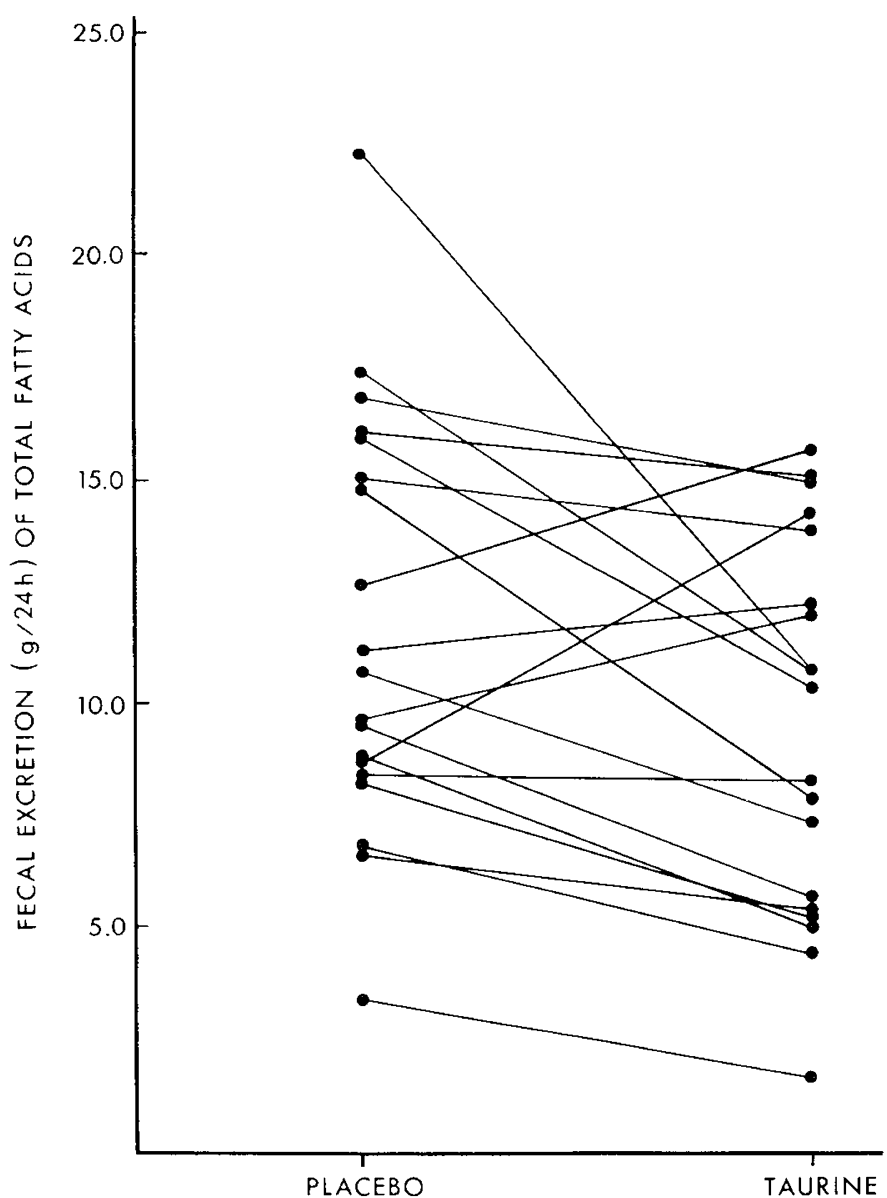

Fig. 1. Individual response of fecal fatty acid excretion to taurine. Of 19 patients, 14 showed a decrease of steatorrhea. Taurine was consistently effective in the seven patients with a greater degree of steatorrhea $(>13$ $\mathrm{g} /$ day) and the response was more pronounced than in the others.

Table 1. Effect of taurine on fecal fat and on the pattern of excreted fatty acids

\begin{tabular}{crrrrrrrrr}
\hline Treatment & $C_{14: 0}$ & $C_{16: 0}$ & $C_{16: 1}$ & $C_{18: 0}$ & $C_{18: 1}$ & $C_{18: 2}$ & $C_{18: 3}$ & $C_{20: 0}$ & Total \\
\hline Placebo & 0.36 & 2.8 & 0.16 & 2.1 & 3.66 & 1.38 & 0.13 & 0.13 & 11.7 \\
$(n=19)$ & \pm 0.06 & \pm 0.3 & \pm 0.03 & \pm 0.2 & \pm 0.44 & \pm 0.22 & +0.04 & \pm 0.01 & \pm 1.1
\end{tabular}

Taurine $\quad \begin{array}{lllllllll}0.30 & 2.2 \dagger & 0.13 & 1.6 \dagger & 3.20 & 1.24 & 0.06 & 0.11 \dagger & 9.5 \dagger\end{array}$ $(n=19) \quad \pm 0.05 \pm 0.3 \pm 0.02 \pm 0.2 \pm 0.37 \pm 0.22 \pm 0.01 \pm 0.01 \pm 1.0$

* Only those fatty acids accounting for more than $1 \%$ of the total are shown. All values $(\tilde{x} \pm S E)$ are expressed in $g / 24 h$.

+ Paired $t$ test; $p<0.05$.

$\mathrm{g} / 24 \mathrm{~h}$ and did not differ from the figure of $2.01 \pm 0.32 \mathrm{~g} / 24 \mathrm{~h}$ documented while the subjects were on taurine which contributed only $3.4 \mathrm{mg} / \mathrm{kg} /$ day to their daily nitrogen intake.

The total plasma fatty acids $(\mathrm{mg} / \mathrm{dl})$ and individual fatty acids, expressed as a percentage of the total, did not differ in the 10 patients who had the most significant degree of steatorrhea. All had detectable amounts of 5,8,11 eicosatrienoic acid (C20:3 $\omega 9$ ). Concentrations on taurine $(0.46 \pm 0.04)$ were the same as on placebo $(0.48 \pm 0.10)$. The ratio of $\mathrm{C} 20: 3 \omega 9$ over C20:4 $\omega 6$ (arachidonic acid) showed no change: it was $0.086 \pm 0.013$ on taurine and $0.088 \pm 0.016$ on placebo. Fasting cholesterol and triglyceride levels $(\mathrm{mg} / \mathrm{dl})$ were the same on taurine $(118 \pm 4$ and $99.4 \pm 20.7)$ as on placebo $(113 \pm 4$ and $78.7 \pm 9.4)$.

Of 18 patients in whom growth data were obtained, 11 showed an increased weight velocity while only eight showed an improvement in height velocity during the 6-month treatment period with taurine. The average $(\bar{X} \pm S E)$ weight increase, expressed as a percentage of the predicted increase for age, was $117.1 \pm 16.5$ on taurine compared to $83.4 \pm 11.3$ on placebo for the entire group. However, the difference was of borderline significance as the $p$ value was $<0.1$ (Fig. 3). Although children on taurine had an average percentage increase of linear growth to $110.7 \pm 10.6$ which was greater than the corresponding figure of $95.3 \pm 7.8$ obtained while they were on placebo there was a wide overlap (Fig. 3). Further analysis of the data showed that there was no carry over effect of taurine which could have interfered with the growth response to treatment (25).

\section{DISCUSSION}

This study has shown that a taurine supplement of $30 \mathrm{mg} / \mathrm{kg} /$ day administered over 6 months in a two-period single blind cross-over trial had a beneficial effect on fat malabsorption and produced a marginally significant increase in weight velocity.

The experimental protocol preempted a strict double-blind design. During encounters with patients, the first author, P.B.D., was aware of the treatment (placebo or taurine) being given. In that sense it was a single-blind study. However, analysis of growth data and processing of biological samples was carried out in a strict double-blind fashion. The possibility of interaction between treatments which could have affected the results was ruled out by appropriate testing (25). All patients were evaluated by one of the authors, P.M., prior to entrance into the study. In the majority, the disease was under good control as only two had a

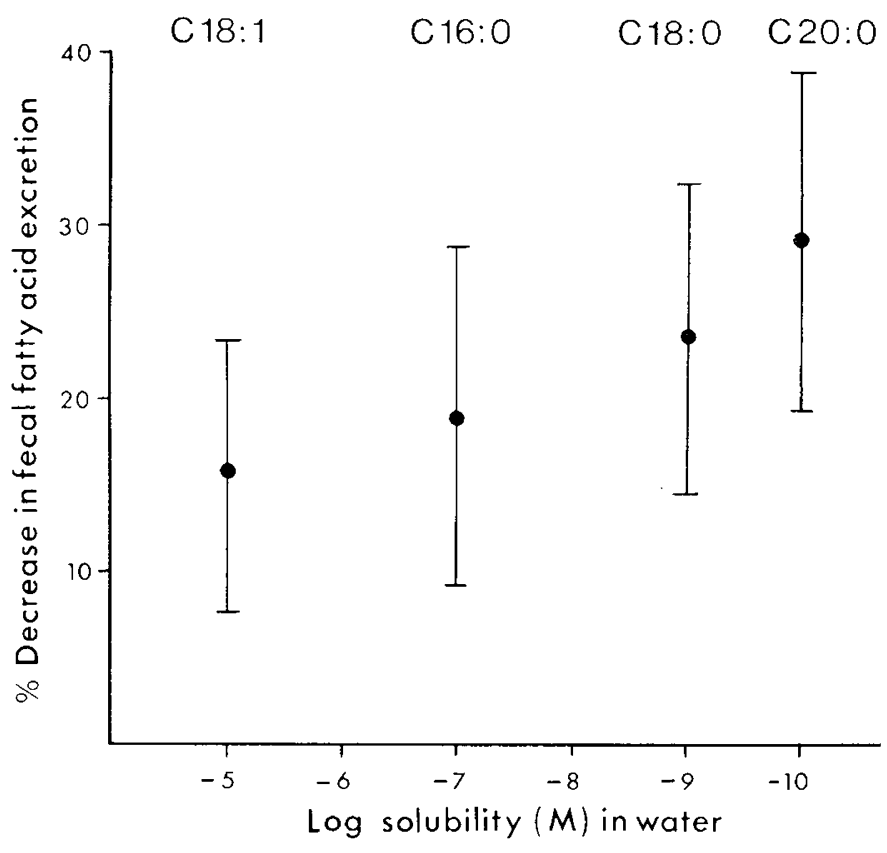

Fig. 2. Effect of taurine on the excretion of long-chain fatty acids as a function of their solubility. The percentage decrease of the four fatty acids $(\overline{\mathrm{X}} \pm \mathrm{SE})$ accounting for $75 \%$ of the total fat loss is plotted against their water solubility. The regression line $(\mathrm{y}=2.6 \mathrm{x}+1.69)$ and the correlation coefficient $(r=0.96)$ were both highly significant $(p<0.01)$.

Table 2. Effect of taurine on sterol excretion

\begin{tabular}{cccc}
\hline Treatment & Neutral sterols & Acidic sterols & Total \\
\hline Placebo & 782.3 & 401.8 & 1184.1 \\
$(n=10)$ & $\pm 86.2^{*}$ & \pm 37.6 & \pm 104.0 \\
& & & \\
Taurine & 682.7 & 372.6 & 1055.3 \\
$(n=10)$ & \pm 105.9 & \pm 58.7 & \pm 148.1 \\
\hline
\end{tabular}

* All values $(\overline{\mathrm{x}} \pm \mathrm{SE})$ are expressed in $\mathrm{mg} / 24 \mathrm{~h}$. 

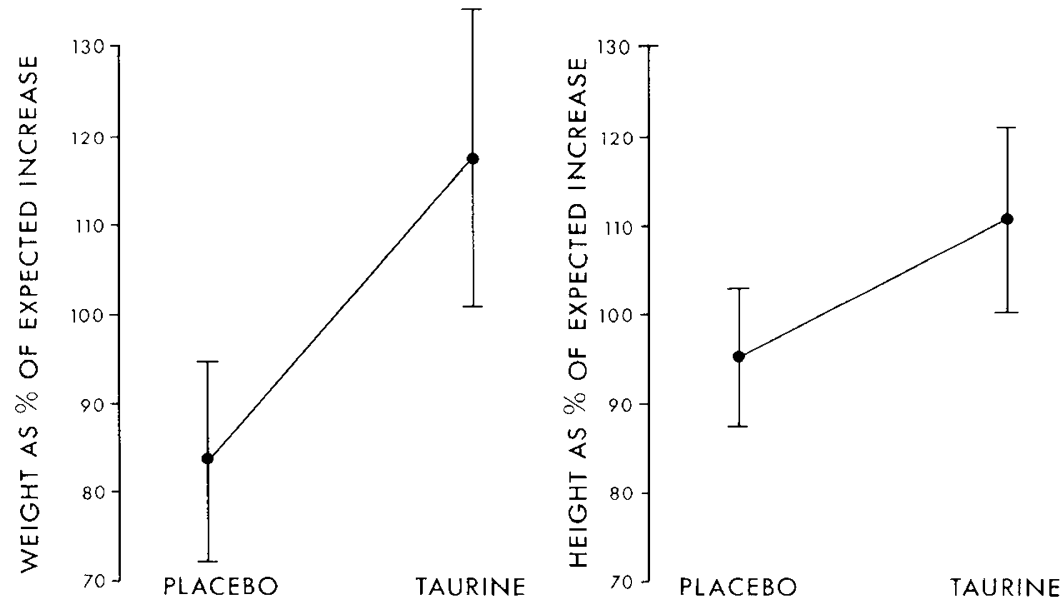

Fig. 3. Growth rate in response to taurine. The weight and height velocities expressed as percentage of expected for age $(\bar{x} \pm \mathrm{SE})$ in 18 patients supplemented with taurine for a period of 6 months.

Shwachman score below 71. Although compliance of the 22 children and their families had been predicted to be excellent, three dropped out of the study.

Taurine supplementation in healthy adults led to a reversal of the $G / T$ conjugation ratio or at least to a decrease in the $G / T$ ratio of conjugated bile acids $(28,29)$. However, neither of these studies addressed the issue of the physiological implications of shifting the conjugation pattern on fat absorption. On the other hand, two studies conducted in preterm infants showed that adding taurine to formulas to equal concentrations present in human milk failed to improve lipid absorption $(5,42)$. Although the change in $G / T$ ratios as a result of taurine supplementation was studied only in two patients, it is reasonable to predict that a change in the conjugation pattern also occurred in the others. It has been shown by Sjovall (29) that the effect of taurine feeding, $1.5-4.5 \mathrm{~g} /$ day, was fully apparent within 5 days. The amount administered for 6 months in the present study corresponds to a dosage of more than $2 \mathrm{~g}$ /day in adults.

As the study was conducted on an ambulatory basis, no attempt was made to monitor dietary intake of fat. It was assumed that variations would be minimized by using each patient as his own control in a cross-over trial. The majority of patients exhibited a decrease in fat loss. Two important observations were made: first, the degree of improvement brought about by taurine was linearly related to the degree of steatorrhea noted on placebo and, second, the fecal loss of the nonpolar, less soluble fatty acids (long-chain saturates) was more extensively reduced. The findings suggest that a shift in the conjugation pattern probably improved the intraluminal phase of fat digestion. At this juncture it is not possible to say whether it is the lipolytic phase, the micellar dispersion step, or both since they are interdependent and closely interrelated. Bile salts are essential in order for pancreatic lipase to adsorb to the lipid-water interface of the triglyceride droplet. They have "squatter's rights" and will dislodge other surface active dietary constituents such as proteins and clear the surface for the colipase-lipase complex (30). Bile acids play a central role for the solubilization of lipolytic products. It has been shown that their physicochemical properties determine their physiological function (31). Glycine conjugates are capable of dispersing more lipids and have a lower critical micellar concentration than corresponding taurine conjugates. However, these advantages are countered by their tendency to come out of solution in an acidic duodenum and by their greater extent of passive absorption in the jejunum compromising micellar solubilization of lipids distally. The decrease in steatorrhea observed in this study may, therefore,be related to improvement in the formation of micelles which transport products of lipolysis across the unstirred water layer (32).
Further indication that taurine favorably affected the shuttle of digested fat between the bulk water phase and the absorptive surface is derived from the data on the fecal sequestration of individual fatty acids. The response to taurine affected mainly the long-chain saturates and was inversely proportional to their water solubility values. The differences between palmitic and linoleic acid in terms of absorbability relates to the lesser availability of the former for incorporation into micelles and to its slower uptake by jejunal absorptive cells (33).

In contrast to other dietary lipids which undergo chemical changes before forming micelles, the bulk $(85-90 \%)$ of dietary cholesterol and all of biliary cholesterol are unesterified. Free cholesterol requires the presence of bile salts to overcome the resistance of the unstirred water layer. Bile salts vary in their capacity to promote cholesterol absorption. Dihydroxy bile acids are inferior to the trihydroxy forms in this regard (34) and taurine conjugates in vitro are less efficient than glycine conjugates for the solubilization of cholesterol monohydrate (35). This is perhaps the reason why administration of taurine had no effect on fecal cholesterol excretion. The extent of bile acid loss in the stools did not change with taurine. As bile acid loss reflects their rate of synthesis, these data confirm studies in normal adults (28) and in preterm infants (5). The absence of alterations in the relative proportion of the two primary bile acids and of their respective degradation products suggest that the predominance of taurine conjugates do not bring about selective changes in the pattern of bile salt synthesis or in their extent of microbial degradation (15).

As taurine did not affect the excretion of linoleic or of linolenic acid, it is not surprising that the plasma fatty acid patterns did not differ. The relative percentage of total plasma fatty acids accounted by $\mathrm{C} 20: 3 \omega 9$ (5-8-11 eicosatrienoic acid) was also unchanged and comparable to other published values in $\mathrm{CF}$ on conventional diets (36). Since it was recently suggested that plasma lipids and lipoproteins are influenced by malabsorption in CF (37), triglycerides and cholesterol were monitored but no difference was observed during treatment with taurine. Neither in adults (38) nor in preterm infants (39) was taurine shown to modify plasma cholesterol levels.

It has been proposed that taurine plays a role as a modulator of growth (1). Two species of infant primates (cebus and cynomolgus) were shown to depend on a dietary source of taurine for maximum growth measured by weight gain (40). However, these observations remain unexplained since dietary intake and $a b-$ sorption were not examined. In preterm infants, taurine had no effect on growth or on fat absorption $(39,41)$. The only indication that taurine could directly influence growth in man comes from human lymphoblastoid cells cultured in a taurine-supplemented 
medium (42). In the present study, the observation that both mean weight and height velocities, which were below expected values for age during the placebo period, responded to taurine by surpassing expected values is of interest. Should these data which show only a trend be confirmed, one would still have to determine if the growth-promoting effect of taurine is a direct one or is mediated by a decrease in energy loss. In the present study, energy intake was not monitored but questionnaires failed to reveal a change during the two treatment periods and the data show that taurine supplements favored a more complete fat absorption. Although a cause and effect relationship between the fat excretion and the marginal improvement of growth cannot be firmly established, it is the most likely explanation for our findings.

Insufficient food intake in the face of increased requirements imposed by infection and chronic lung disease is now considered the more significant cause of malnutrition in CF (43). A poor response of the lipolytic phase defect to available pancreatic enzyme supplements (44) and concomitant alterations of bile salt metabolism $(9,45)$, compromising micellar solubilization of lipolytic products, are also important factors. Claims of added efficacy of a conventional pancreatic enzyme preparation with added bile salts have not been substantiated (46). Taurine supplementation appears to be promising as an adjuvant form to therapy, particularly in patients with a significant degree of steatorrhea despite adequate pancreatic supplementation. A better definition of its effects on the absorption of lipids and on the metabolism of bile salts, as well as a clearer demonstration of its repercussions on nutrition and growth, are necessary before recommending its general use.

Acknowledgments. The authors thank Merck Frosst Canada Inc. for preparing the taurine capsules.

\section{REFERENCES}

1. Gaull GE 1983 Taurine in human milk: growth modulator or conditionally essential amino acid? J Pediatr Gastroenterol Nutr 2(suppl):S266-S271

2. Hayes KC, Sturman JA 1981 Taurine in metabolism. Ann Rev Nutr 1:401425

3. Sturman JA 1983 Taurine in nutrition research. In: Kuriyama K, Huxtable RJ (eds) Sulfur Amino Acids: Biochemical and Clinical Aspects. Alan R. Liss Inc, New York, pp 281-295

4. Hardison WGM 1978 Hepatic taurine concentration and dietary taurine as regulators of bile acid conjugation with taurine. Gastroenterology 75:71-75

5. Watkins JB, Jarvenpaa AL, Szczepanik-Van Leeuwen P, Klein PD, Rassin DK, Gaull G, Raiha NCR 1983 Feeding the low-birth weight infant: V. Effects of taurine, cholesterol, and human milk on bile acid kinetics. Gastroenterology 85:793-800

6. Cano N, Marteau C, Constanzo JD, Martin J, Richieri J-P, Mas J-C, Crotte C, Gérolami A 1982 Etude de la composition biliaire sous nutrition entérale totale chez l'homme. Gastroenterol Clin Biol 6:673-678

7. Rigo J, Senterre J 1977 Is taurine essential for the neonates? Biol Neonate 32:73-76

8. Garbutt JT, Heaton KW, Lach L, Tyor MP 1969 Increased ratio of glycine to taurine-conjugated bile salts in patients with ileal disorders. Gastroenterology 561:711-720

9. Roy CC, Weber AM, Morin CL, Combes JC, Nusslé D, Mégevand A, Lasalle R 1977 Abnormal biliary lipid composition in cystic fibrosis. N Engl $\mathbf{J}$ Med 297:1301-1305

10. Davidson GP, Robb TA, Kirubakaran C 1984 Conjugated bile acids in serum and secretions of cystic fibrosis patients. In: Lawson D (ed) Cystic Fibrosis: Horizons. Proceedings of the 9th International Cystic Fibrosis Congress, John Wiley and Sons, New York, p 301-323

11. Harries JT Muller DPR, McCollumn JPK, Lipson A, Roma E, Norman AP 1979 Intestinal bile salts in cystic fibrosis. Arch Dis Child 54:19-24

12. Regan PT, Malagelada J-R, Dimagno EP, Go VLM 1979 Reduced intraluminal bile acid concentrations and fat maldigestion in pancreatic insufficiency: correction by treatment. Gastroenterology 77:285-289

13. Krag E, Phillips SF 1974 Active and passive bile acids absorption in man. J Clin Invest 53:1686-1694

14. Linnet K 1983 Postprandial plasma concentrations of glycine and taurine conjugated bile acids in healthy subjects. Gut 24:249-252

15. Hepner GW, Sturman JA, Hofmann AF, Thomas PJ 1973 Metabolism of steroid and amino acid moieties of conjugated bile acids in man. III. Cholyltaurine (taurocholic acid). J Clin Invest 52:433-440

16. Roy CC, Weber AM, Morin CL, Lepage G, Brisson G, Yousef I, Lasalle R 1982 Hepatobiliary disease in cystic fibrosis: a survey of current issues and concepts. J Pediatr Gastroenterol Nutr 1:469-477

17. Courbes de croissance et de développement physique de l'enfant canadienfrancais 1983 Centre de recherche sur la croissance humaine. Montréal

18. Shwachman H, Kulczyckii L 1958 Long-term study of one hundred five patients with cystic fibrosis. Am J Dis Child 96:6-15

19. Macdonald IA, Bokkenheuser VD, Winter J, McLennon AM, Mosbach EH 1983 Degradation of steroids in the human gut. J Lipid Res 24:675-700

20. Lepage G, Roy CC 1984 Improved recovery of fatty acids by gas-liquid chromatography through direct transesterification without prior extraction or purification. J Lipid Res 25:1391-1396

21. Miettinen TA, Ahrens EH, Grundy SM 1965 Quantitative isolation and gas liquid chromatographic analysis of total dietary and fecal neutral steroids. $J$ Lipid Res 6:411-424

22. O'Brien D, Ibbott FA, Rodgerson DO 1968 Determination of total nitrogen in tissue and biological fluids by the Kjeldahl method. In: Laboratory Manual of Pediatric Microbiochemical Techniques. Harper and Row Publishers, New York, pp 238-240

23. Lipid Research Clinics Program, Manual of Laboratory Operations 1974 DHEW Publication no (NIH), Bethesda, 75-628, vol 1

24. Tanner JM, Whitehouse RH, Takaishi M 1966 Standards from birth to maturity for height, weight, height velocity and weight velocity: British children, 1965, Part II. Arch Dis Child 41:613-635

25. Hills M, Armitage P 1979 The two period cross-over clinical trial. Br J Clin Pharmacol 8:7-20

26. Dixon WJ, Massey FJ 1969 Regression and correlation. In: Introduction to Statistical Analysis. McGraw-Hill Book Co, New York, pp 193-221

27. Hofmann AF, Mekhjian 1973 Bile acids and the intestinal absorption of fat and electrolytes in health and disease. In: Nair PP, Kritchevsky D (eds) The Bile Acids. Plenum Press, New York, pp 103-152

28. Hardison WGM 1983 Effect of bile acid conjugation pattern on bile acid metabolism in normal humans. Gastroenterology 84:617-620

29. Sjovall J 1959 Dietary glycine and taurine on bile acid conjugation in man. Proc Soc Exp Biol Med 100:676-678

30. Hofmann AF 1975 Lipase, colipase, amphipathic dietary proteins, and bile acids: new interactions at an old interface. Gastroenterology 75:530-532

31. Hofmann AF 1968 Molecular association in fat digestion. Interaction in bulk of monolein, oleic acid and sodium oleate with dilute, micellar bile salt solutions. Adv Chem 84:53-59

32. Westergaard H, Dietschy JM 1976 The mechanism whereby bile acid micelles increase the rate of fatty acid and cholesterol uptake into the intestinal mucosal cell. J Clin Invest 58:97-108

33. Ockner RK, Pittman JP, Yager JL 1972 Differences in the intestinal absorption of saturated and unsaturated long chain fatty acids. Gastroenterology 62:981992

34. Watt SJ, Simmonds WJ 1984 Effects of four taurine-conjugated bile acids on mucosal uptake and lymphatic absorption of cholesterol in the rat. J Lipid Res 25:448-455

35. Carey MC 1983 Measurement of the physical-chemical properties of bile salt solutions. In: Barbara L (ed) Bile Acids in Gastroenterology. MTP Press Ltd, Lancaster, pp 19-516

36. Dodge JA, Yassa JG 1980 Food intake and supplementary feeding programmes. In: Sturgess JM (ed) Prespectives in Cystic Fibrosis 8th International Congress. CF Foundation, Toronto, pp 125-136

37. Schoni M, Kraemer R, Ruedeberg A, Lentze MJ, Mordasani RC, Riesen WF, Klay MP, Rossi E 1984 Long-term cimetidine in children with cystic fibrosis: a randomized double-blind study. Pediatr Res 18:66-70

38. Truswell AS, McVeigh S, Mitchell WD, Bronte-Stewart B 1965 Effect in man of feeding taurine on bile acid conjugation and serum cholesterol levels. $\mathbf{J}$ Atherosc Res 5:526-529

39. Jarvenpaa AL, Raiha NCR, Rassin DK, Gaull GE 1983 Feeding the low-birthweight infant: I. Taurine and cholesterol supplementation of formula does not affect growth and metabolism. Pediatrics 71:171-178

40. Hayes KC, Stephan ZF, Sturman JA 1980 Growth depression in taurinedepleted infant monkeys. J Nutr 110:2058-2064

41. Okamoto E, Rassin DK, Zucker CL, Salen GS, Heird WC 1984 Role of taurine in feeding the low-birth-weight infant. J Pediatr 104:936-940

42. Gaull GE, Wright GE, Tallen HH 1983 Taurine in human lymphoblastoid cells: uptake and role in proliferation. In: Kuriyama $J$, Huxtable RJ (eds) Sulfur Amino Acids: Biochemical and Clinical Aspects. Alan R. Liss, New York, pp 297-303

43. Shwachman H 1981 Nutritional considerations in the treatment of children with cystic fibrosis. In: Suskind RM (ed) Textbook of Pediatric Nutrition. Raven Press, New York, pp 511-525

44. DiMagno E, Malagelada J, Go V, Moertel C 1977 Fate of orally ingested enzymes in pancreatic insufficiency. N Engl J Med 296:1318-1322

45. Watkins JB, Tercyak AM, Szczepanik P, Klein PD 1977 Bile salt kinetics in cystic fibrosis: Influence of pancreatic enzyme replacement. Gastroenterology 73:1023-1028

46. Nassif EG, Younoszai MK, Weihberger MM, Nassif CM 1981 Comparative effects of antacids, enteric coating, and bile salts on the efficacy of oral pancreatic enzyme therapy in cystic fibrosis. J Pediatr 98:320-323 